\title{
Economic burden of vertigo: a systematic review
}

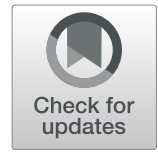

Eva Kovacs ${ }^{1,2^{*}}$, Xiaoting Wang ${ }^{1}$ and Eva Grill ${ }^{1,2,3}$

\begin{abstract}
Background: Vertigo, a highly prevalent disease, imposes a rising burden on the health care system, exacerbated by the ageing of the population; and further, contributes to a wide span of indirect burden due to reduced capacity to work or need of assistance in activities of daily living. The aim of this review was to summarise the evidence on the economic burden of vertigo.

Methods: All original studies published between 2008 and 2018 about the economic evaluation of peripheral or central vestibular vertigo in developed countries were considered eligible, unrestricted to setting, health care provider, or study type.

Results: The electronic search in three databases identified 154 studies from which 16 qualified for inclusion. All studies presented partial economic evaluation referring to a variety of vestibular vertigo including unspecified vertigo. Nine studies presented monetised cost results and seven studies reported health care utilization. Direct costs derived mainly from repeated and not well-targeted consultations at all levels of health care, excessive use of diagnostic imaging, and/or of emergency care. Considerable societal burden was caused by decreased productivity, mainly due to work absenteeism.

Conclusion: To the best of our knowledge, this is the first systematic review of the existing evidence of the economic burden of vertigo. The lack of conclusive evidence revealed apparent targets of future research. First, studies of diagnostics and therapies for vestibular disease should include cost-effectiveness considerations. Population-based studies of health services utilization should include simple vestibular assessments to get more reliable estimates of the burden of disease and associated costs on the level of the general population. Further, clinical and population-based registries that include patients with vestibular disease, should consider collecting long-term data of societal burden. Primary data collection should increasingly include assessment of health care utilization e.g. by linking their diagnoses and outcomes to routine data from health insurances.
\end{abstract}

Keywords: Vestibular vertigo, Dizziness, Cost of illness, Health care costs cost analysis, Health care utilization

\section{Background}

Vertigo and dizziness, belonging to the most frequent symptoms with an estimated lifetime prevalence of $17-$ $30 \%[1]$, cover diseases and conditions of various origin $[2,3]$. In a narrower sense, vertigo refers to peripheral or central vestibular diseases with a lifetime prevalence of up to $10 \%[1,4]$ and a yearly incidence of $1.4 \%[4]$. The

\footnotetext{
* Correspondence: Eva.Kovacs@med.uni-muenchen.de

'Institute for Medical Information Processing, Biometrics and Epidemiology, Ludwig-Maximilians-Universität München, Munich, Germany

${ }^{2}$ German Center for Vertigo and Balance Disorders, Faculty of Medicine,

University Hospital, Ludwig-Maximilians-Universität München, Marchioninistr.

15, 81377 Munich, Germany

Full list of author information is available at the end of the article
}

most prevalent types of peripheral vestibular vertigo are benign paroxysmal positional vertigo (BPPV), Meniere's disease (MD), vestibular neuritis and bilateral vestibulopathy; vestibular migraine is one of the most common examples of central vestibular vertigo $[3,5]$.

Arguably, vertigo and dizziness are among the main drivers for health care utilization from primary care [6-8] through specialist care [9] to tertiary level hospitals [10]; therefore may have a high impact on direct costs in industrialized countries. The increasing prevalence of vertigo in older population [11] further contributes to this burden of health care [12]. 
Individuals with acute symptoms may present at all levels of the health system including emergency services [13, 14]; however most instances of vertigo might be diagnosed and treated at the primary care level [15]. This is often not the case, leading to unjustified diagnostic procedures, prolonged time to diagnosis and repeated specialist consultations [6]. One major driver of direct health care costs may be the overutilization of imaging procedures, which actually would have a well-defined but limited role in differentiating vestibular disease from rare but life-threatening conditions such as stroke [16]. Regarding therapy in BPPV, the most prevalent type of vertigo in older adults [4], liberatory manoeuvres [17, 18] may bring fast relief [19]. Pharmacotherapy has its place in a limited number of pathologies [20]; vestibular rehabilitation [21] should be offered to all patients with vestibular deficiency [22].

Regarding indirect costs, vertigo can be a reason for sick leave and occupational disability. In a study from the United Kingdom (UK) and Italy, patients reported a mean of 7 days absence from work due to dizziness in the previous 6 months [23]. From those patients still working, over $50 \%$ felt that their work efficiency had dropped [23]; over one fourth of them had changed their jobs and 21\% had quit work [23]. Likewise, in Belgium, more than half of the patients of a tertiary dizziness center reported having been on sick leave due to dizziness, and $12 \%$ were completely unable to return to work [24].

Also, vestibular disease may cause considerable restrictions of activities of daily living [23] and quality of life [25]. Loss of quality of life from vestibular disease was recently estimated to amount to a total of 64,929 USD lifetime economic burden per patient, or in a total lifetime societal burden of 227 billion USD for the USA population over 60 years of age [26].

As financial burden of disease seems to be considerable for vertigo and dizziness, we aimed to summarise the evidence from available quantitative studies in a systematic way. Specifically, we aimed to summarize information on costs arising from diagnosis, referral or therapy.

\section{Methods}

In this review the Preferred Reporting Items for Systematic Reviews and Meta-Analyses [27] was followed.

\section{Search strategy and eligibility criteria}

All original studies regarding any kind of economic evaluation of vertigo were considered irrespective of study design or perspective (e.g. payer or society).

The detailed search strategy for the electronic databases Medline, EMBASE, and Cochrane Library is presented in the Additional file 1 Beside the general terms "vertigo" or "dizziness", the search terms were compiled to cover the above listed most prevalent vertigo types of peripherial or central vestibular origin, and functional vertigo; including both their referring Medical Subject Headings (MeSH) terms and additional free text. Restricting the search to title and abstract ensured to focus on studies handling vertigo or dizziness as the main topic of the study. Vestibular Schwannoma was excluded with respect to its surgical treatment being not comparable with the conservative management of all other vertigo types. $\mathrm{MeSH}$ terms representing a broad range of economic evaluation were completed with a free text search.

With respect to the comparability of economic results, developed countries according to the categorization of the United Nations Statistics Division [28] were selected. The hits were restricted to being published in English in the last 10 years, i.e. between October 2008-01. October 2018.

Full texts were retrieved via the online library service of the Ludwig-Maximilians-Universität München. We contacted two authors for further information unsuccessfully. The search in the electronic databases was not extended by a handpicked search. Study selection was performed by two independent researchers (XW and EK). Disagreement was resolved by discussion or in lack of consensus by the decision of a third researcher (EG).

\section{Data collection}

A Microsoft Excel form was prepared (XW) for collecting data of study characteristics, vertigo type(s), and outcome indicators. Assessing methodological quality and risk of bias, the list of Consensus on Health Economic Criteria (CHEC) [29] was applied. One researcher (XW) performed the data extraction and a second researcher (EK) checked the data.

\section{Conversion of the economic results}

Costs expressed in national currencies and in different price years were reported both in original form and converted into 2016 USD using The Campbell and Cochrane Economics Methods Group Evidence for Policy and Practice Information Coordinating Centre (CCEMG -EPPI-Centre) Cost Converter [30]. The converter adjusts the price year according to the Gross Domestic Product deflator index; while conversion between countries/currencies is based on Purchasing Power Parities, in accordance with the recommendation of the Cochrane Handbook for Systematic Reviews [31].

In case of studies reporting health care utilization in units as an outcome, health care utilization in units as an outcome, despite considerable efforts we were not able to retrieve historical unit prices for converting reported units into monetary estimates.

\section{Results}

Study selection

The electronic search identified 154 studies from three databases. After removing duplicates, 104 studies were 
screened by title and abstract according to the eligibility criteria. Inclusion was discussed in 21 cases, resulting in 35 studies qualifying for full-text reading. Disagreement was then solved by discussion in 17 cases, and in lack of consensus in six cases, the third researcher made the decision. Sixteen studies were included in the review. Figure 1 presents the flow of study selection.

\section{Study characteristics}

Detailed description of the original studies, the setting, timeframe, included vertigo type(s), the selection criteria, the main characteristics of the study population, and the reported type of burden was presented in Table 1 . The 16 studies covered seven countries: the USA (seven studies [32-34, 36, 38, 42, 44];), the UK (three studies [41, 45, 47];), Germany (three studies [37, 40, 46];), Canada (one study [39];), Norway (one study [43];) and a multicentre study [35] from which we selected the data referring to the developed countries in Europe, namely the Czech Republic, Germany, Hungary, and Slovenia. Health care providers were primary care [47], emergency department in four studies [33, 34, 39, 42], and hospital in three studies [36, 41, 44]. Two studies covered more than one sector of the health care system [35, 37]; and five studies applied a population-based approach $[32,38,40,45,46]$.

Regarding the type of the vertigo, addressed diseases and symptoms ranged from unspecified patient-reported dizziness [46] to verified vestibular diseases such as unior bilateral vestibular deficiency (UVD, BVD) [36, 44], MD [45], and BPPV [41]. Most of the studies covered a range of central and peripherial vestibular vertigo [40], including undiagnosed vertigo [32-35, 38, 39, 42, 43, 47]; and including functional vertigo as well [37].

The studies reported the burden of vertigo by variuos means: resource use per patient, aggregated to or in rate

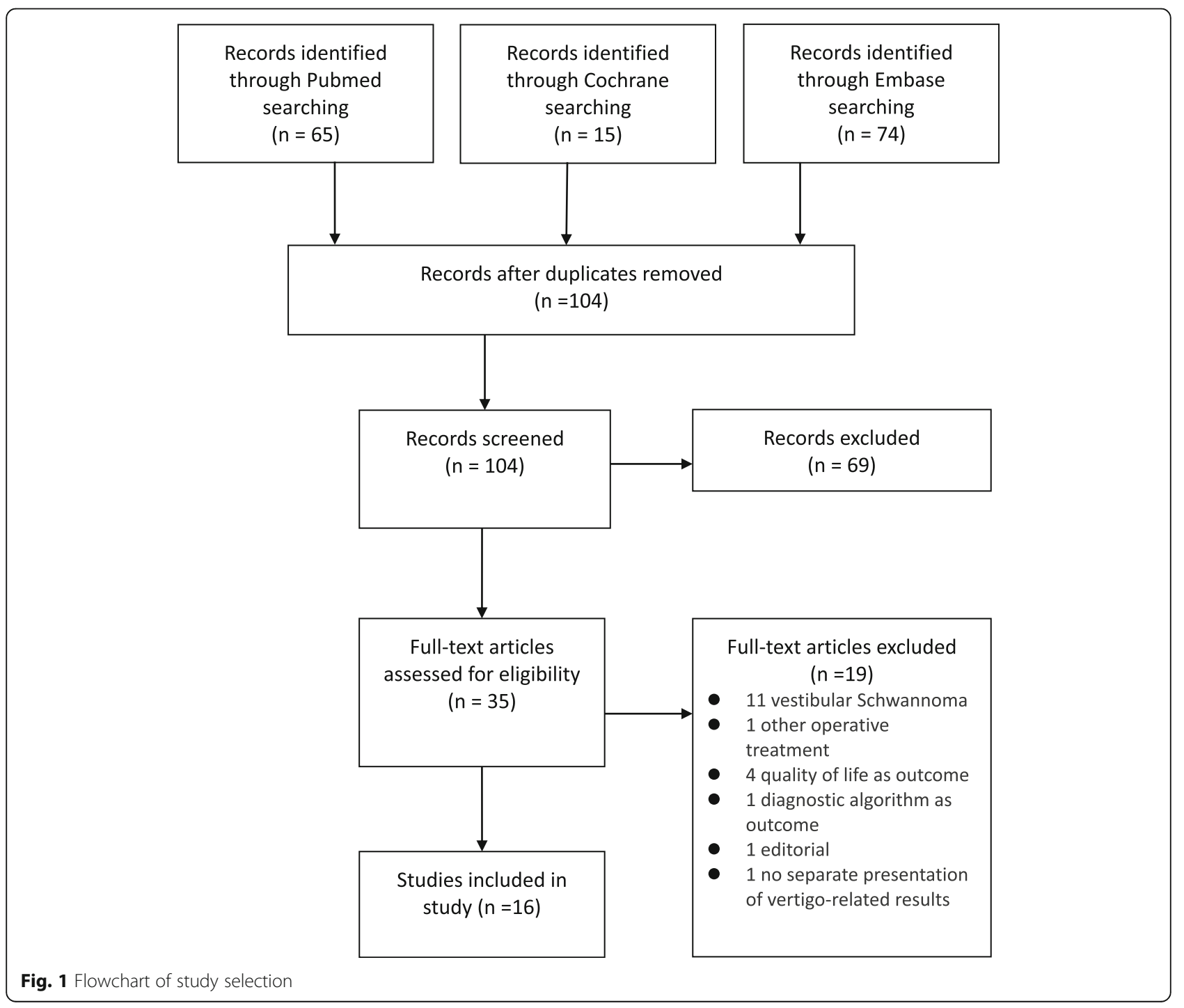




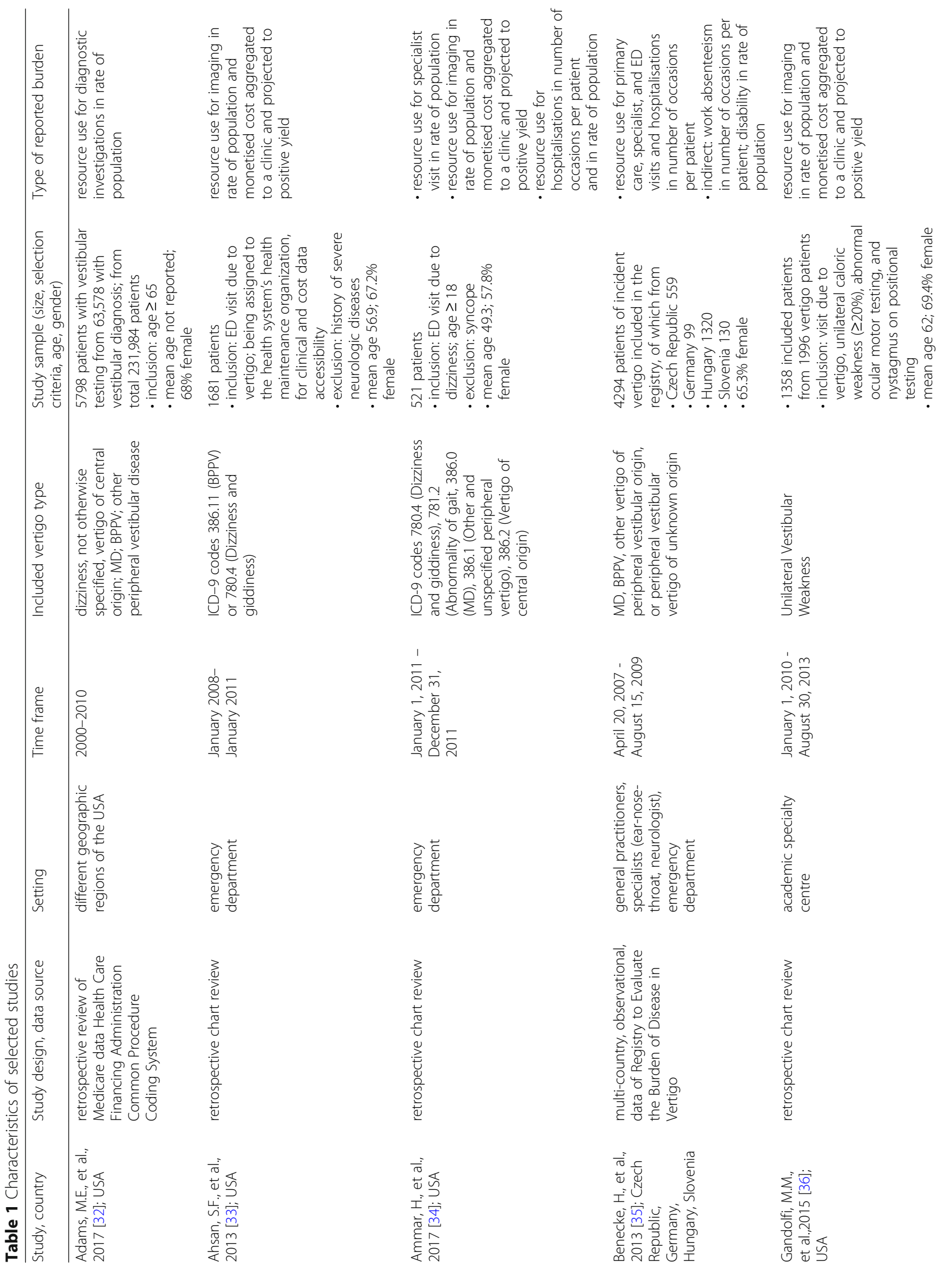




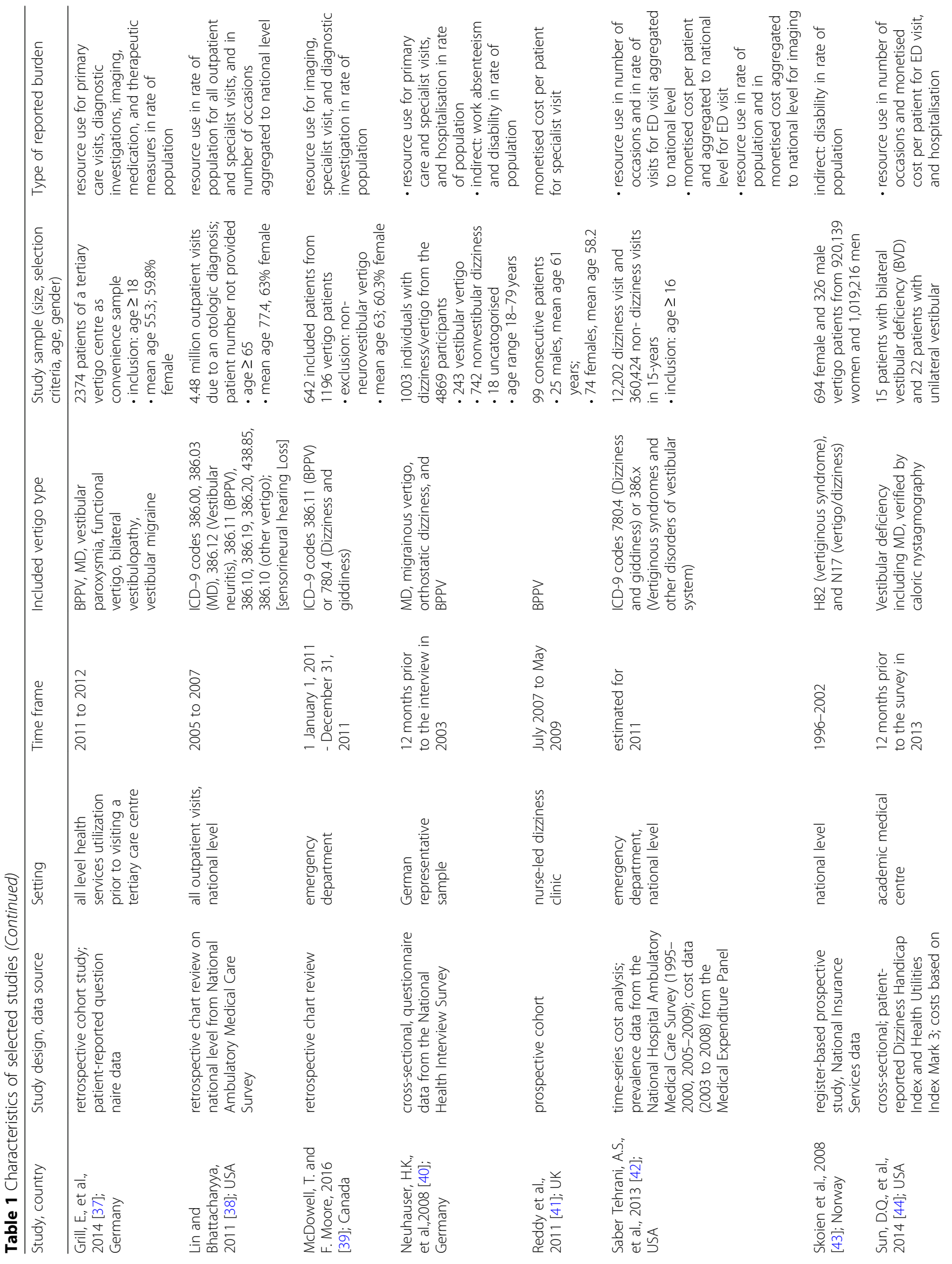


Kovacs et al. Health Economics Review

(2019) 9:37

Page 6 of 14

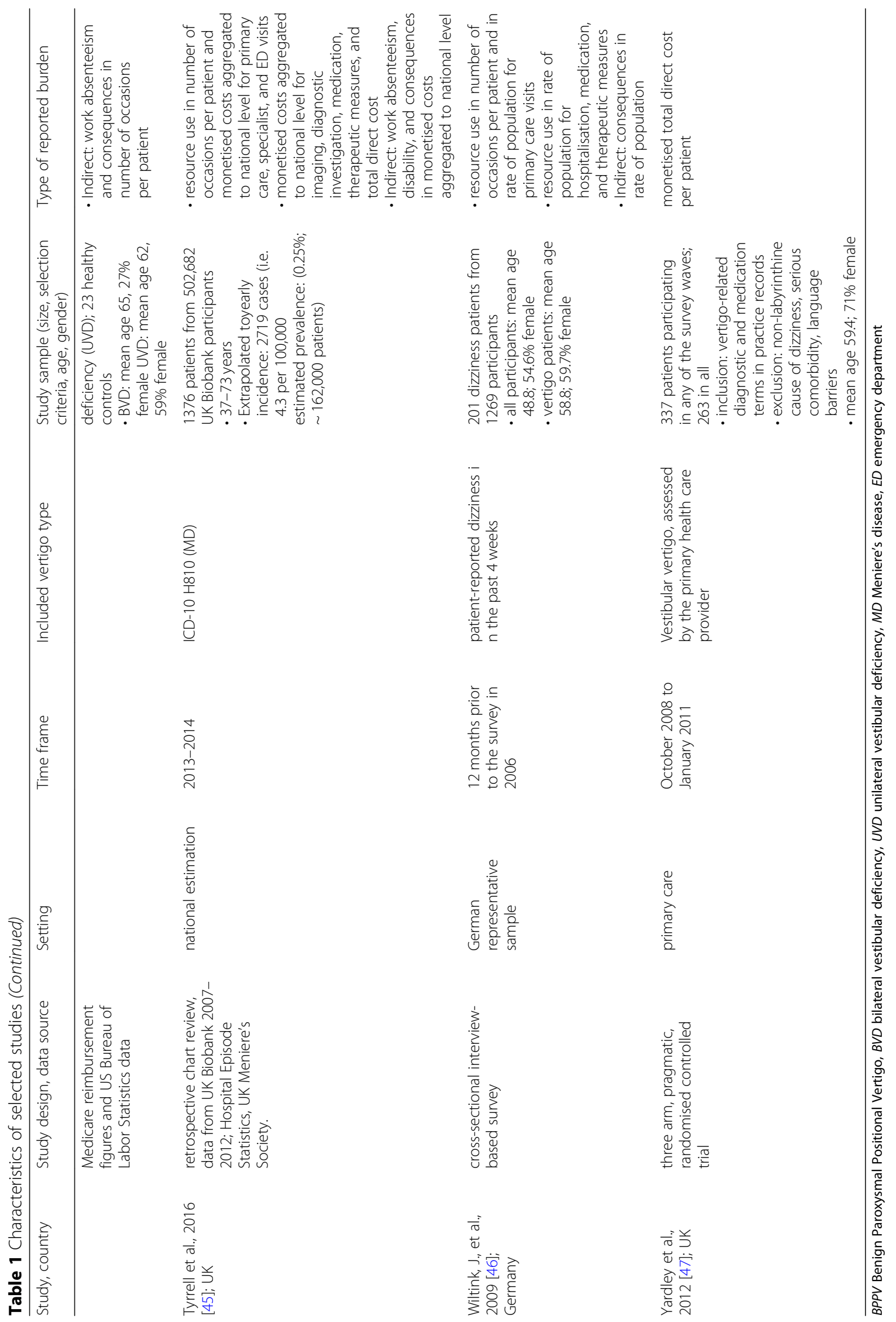


of a certain population; monetised cost either measured or estimated per patient, per diagnostic investigation and/or per positive yield, or on different agggregation level. The applied population covered a wide range from general population, nationally representative patient sample or overall national health care data, or patient population diverse in terms of the above detailed diagnoses and health care services (Table 1).

With two exceptions [41, 47], the studies were observational; quality criteria items referring to an intervention being not applicable. This resulted in a median quality score of six from 19 total of the CHEC (Additional file 2). One of the studies [44] conducted a sensitivity analysis; one study [42] applied inflation adjustment.

\section{Direct costs of vertigo}

Two studies calculated the overall annual cost per patient $[44,45]$, and seven studies reported specific monetised cost components [33, 34, 36, 41, 42, 44, 47]. Seven studies reported health care utilization [32, 35, 37, 39, 40, 43, 46]. Table 2 demonstrates the detailed direct costs (both in original currency and in 2016 USD) and/ or health care utilization data reported by the studies.

\section{Medical consultations}

From the unselected adult (17-79 year-old) population $1.8 \%$ had a consultation in the previous 12 months [40]. In Germany these consultations were roughly equally distributed between primary health care and specialists [40]; in the USA the contribution of primary health care providers was $14.3 \%$ [38].

Separated according to the level of health care, the range of primary care consultations was 1.1-2.6 occasion, and the range of specialist consultation was $0.8-1.8$ [35] within the 3 month observation period in European countries. More than two consultations occurred in $61.3 \%$ of the vertigo patients [37]. Vestibular vertigo patients had more consultations than patients with nonvestibular vertigo [40]. Co-morbid anxiety increased the number of consultations up to 6.6 (SD 5.4) within the previous 12 months [46]. Higher age also contributed to more consultations $[35,40]$.

\section{Emergency care}

Occasions of emergency care visits ranged from 0.1 to 0.6 [35] within 3 months in European countries, or 0.1 (SD 0.5) to 0.4 (SD 0.8) within 12 months [44] in the USA, the latter corresponding to mean costs of 94-274 (range 0-2374) USD per case [44]. In a USA national overview, 3.9 million emergency care visits in 2011 resulted in 3.9 billion USD total costs, i.e. on average 1004 USD per patient and visit [42].

\section{Hospitalisation}

Hospitalisation in Germany due to vertigo was reported by $1.9 \%$ of the unselected adult population [40]. Lifetime hospitalisation occurred in $10 \%$ of vestibular vertigo patients and in $5 \%$ of patients with non-vestibular vertigo [40].

The number of hospital days ranged from 0.4 to 1.7 days during a 3 month observation period [35] in European countries. In the USA, BVD patients had 1.4 (SD 0.8 ) hospital visits within 12 months, causing a 203 (range 0-348) USD cost [44]. Advanced age contributed to longer hospital stay [35].

\section{Diagnostic procedures}

Patients in Germany underwent on average 3.2 (range 0-6) instrumental diagnostic procedures [37], the older age group receiving significantly less [32, 37]. Economic reporting about diagnostic procedures focused on imaging, being the most frequently used [37], and the most expensive diagnostic procedures accounted for $12 \%$ of the total annual costs for dizziness visits [42]. Prior to referral to a German tertiary balance centre, $82 \%$ of the patients received either magnetic resonance imaging (MRI) or computed tomography (CT) [37].

CT was performed in $22.8 \%$ [42] and up to $50 \%$ [39] of the vertigo patients, depending on the setting, i.e. general patient population or emergency patients, respectively. Each 10-years step in age increased the probability of scanning to 1.4 times [33]. CT use showed an increasing trend in a national-level USA study [42], with an almost two-thirds increase between 2005 and 2009. However, the yielding rate of $\mathrm{CT}$ for vestibular diseases was reported to be low, from $0.74 \%$ [33] to $3.6 \%$ [34]. This resulted in a high diagnostic cost for positive findings, ranging from 54, 540 USD [34] to 176,720 USD [33].

MRI was applied in 5.4\% [33] to $18.6 \%$ [36] of the patients. The yielding rate for vestibular diseases was between $12.2 \%$ [33] and 13.8\% [36] with a cost range for a positive yield of 15,737 USD [36] to 36,025 USD [34].

Other diagnostic methods were less frequent than imaging: head impulse test was performed in $5 \%$ of the patients and the Dix-Hallpike manoeuvre in 31.4\% [39]. Among the listed diagnostic methods, head impulse test had the highest yielding rate for vestibular disease of $29 \%$ [39].

\section{Therapy and medication}

Vertigo patients had on average 1.8 (range 0-8) different therapies; the most frequent therapy was medication (61.0\% of all patients), with mean of 1.8 (range 0-17) drugs per patient [37]. Physical therapy was prescribed in 41.3\% of the patients [37]. The liberatory Epley manoeuvre was performed in $15.3 \%$ of BPPV patients [39]. 
Table 2 Direct costs of vertigo

\begin{tabular}{|c|c|}
\hline Type of health service & Resource use \\
\hline \multicolumn{2}{|l|}{ Medical consultations } \\
\hline \multicolumn{2}{|l|}{ Per person } \\
\hline Primary care provider & $\begin{array}{l}\text { Within } 3 \text { months: } 1.1 \text { (Czech Republic), } \\
\text { 1.8 (Germany), } 2.6 \text { (Hungary), } 2.4 \\
\text { (Slovenia) (Benecke et al., } 2013 \text { [35]) } \\
\text { Per year: } 5 \text { (Tyrrell et al., } 2016 \text { [45]), } 6.6 \\
\text { (with comorbid anxiety), } 6.4 \text { (without } \\
\text { comorbid anxiety) (Wiltink et al., } 2009 \\
\text { [46]) }\end{array}$ \\
\hline Specialist & $\begin{array}{l}\text { Within } 3 \text { months: } 1.8 \text { (Czech Republic), } \\
\text { 1.2 (Germany), } 1.2 \text { (Hungary), } 0.8 \\
\text { (Slovenia) (Benecke et al., } 2013 \text { [35]) } \\
\text { Per year: } 1 \text { (Tyrrell et al., } 2016[45] \text { ) }\end{array}$ \\
\hline Emergency department & $\begin{array}{l}\text { Within } 3 \text { months: } 0.3 \text { (Czech Republic), } \\
0.2 \text { (Germany), } 0.4 \text { (Hungary), } 0.6 \\
\text { (Slovenia) (Benecke et al., } 2013 \text { [35]) } \\
\text { Per year } 0.3 \text { (0-3) (BVD), } 0.1 \text { (0-2.4) (UVD) } \\
\text { (Sun et al., } 2014 \text { [44]) }\end{array}$ \\
\hline Hospitalisation & $\begin{array}{l}\text { Within } 3 \text { months: } 1.7 \text { (days, Czech } \\
\text { Republic), } 0.4 \text { (days, Germany), } 1.0 \text { (days, } \\
\text { Hungary), } 0.8 \text { (days, Slovenia) (Benecke } \\
\text { et al., } 2013 \text { [35]) } \\
\text { Per year: } 2.7 \text { (days, all ED vertigo), } 6.7 \\
\text { (days, central neurological vertigo), } 2.3 \\
\text { (days, non-central vertigo) (Ammar et al., } \\
2017 \text { [34]) } \\
\text { Per year: } 1.4 \text { (occasions, BVD), } 0.7 \\
\text { (occasions, UVD) (Sun et al., } 2014 \text { [44]) }\end{array}$ \\
\hline
\end{tabular}

\section{Aggregated}

Primary care provider

Specialist

Emergency department Per year: 3.9 million (Saber Tehrani et al., 2013 [42])
14.3\% (all outpatient visits) (Lin and Bhattacharyya, 2011 [38]), $1.8 \%$ (incident vertigo, general population), 17.1\% (lifetime) (Neuhauser et al., 2008 [40]), 61.3\% (> 2 visits) (Grill et al., 2014 [37]), $57.1 \%$ (with comorbid anxiety), 33.1\% (without comorbid anxiety) (Wiltink et al., 2009 [46])

4.2\% (neurology), 1.3\% (ENT) (Ammar et al. 2017 [34]), 16.4\% (neurology) (McDowell and Moore, 2016 [39]) $30 \%$ (neurology, lifetime, vestibular vertigo), 12\% (neurology, lifetime, non-vestibular vertigo), 34\% (ear-nose-throat, lifetime, vestibular vertigo), 7\% (ENT, non-vestibular vertigo) (Neuhauser et al., 2008 [40]) $57.0 \%$ (otolaryngology), 21.0\%

(internal medicine), 2.2\% (neurology), 1.2\% (cardiovascular) (Lin and Bhattacharyya, 2011 [38])

25.7\% (all ED visits), trend from $2.7 \%$ in 1995 to $3.8 \%$ in 2015 (costs, all ED visit) (Saber Tehrani et al., 2013 [42])

24.6\% (ED vertigo) (Ammar et al., 2017 [34]), 10\% (lifetime, vestibular vertigo), 5\% (lifetime, non-vestibular vertigo) (Neuhauser et al., 2008 [40]), 8.9\% (with comorbid anxiety), 2.8\% (without comorbid anxiety) (Wiltink et al., 2009 [46])
76 [123] GBP (follow-up visit) (Reddy et al., 2011 [41])

Per year: 274 [289] USD (BVD), 94 [99] USD (UVD) (Sun et al., 2014 [44]), 1004 [1077] USD (any dizziness), 768 [824] USD (otologic / vestibular cause) (Saber Tehrani et al., 2013 [42])

Per year: 203 [214] USD (BVD), 92 [97] USD (UVD) (Sun et al., 2014 [44])

Per year: 35.54 [51.75] million GBP (Tyrrell et al., 2016 [45]

Per year: 10.0 [14.56] million GBP (Tyrrell et al., 2016 [45])

Per year: 3.9 [4.2] billion USD (Saber Tehrani et al., 2013 [42]), 0.68 [0.99] million GBP (Tyrrell et al., 2016 [45]) 
Table 2 Direct costs of vertigo (Continued)

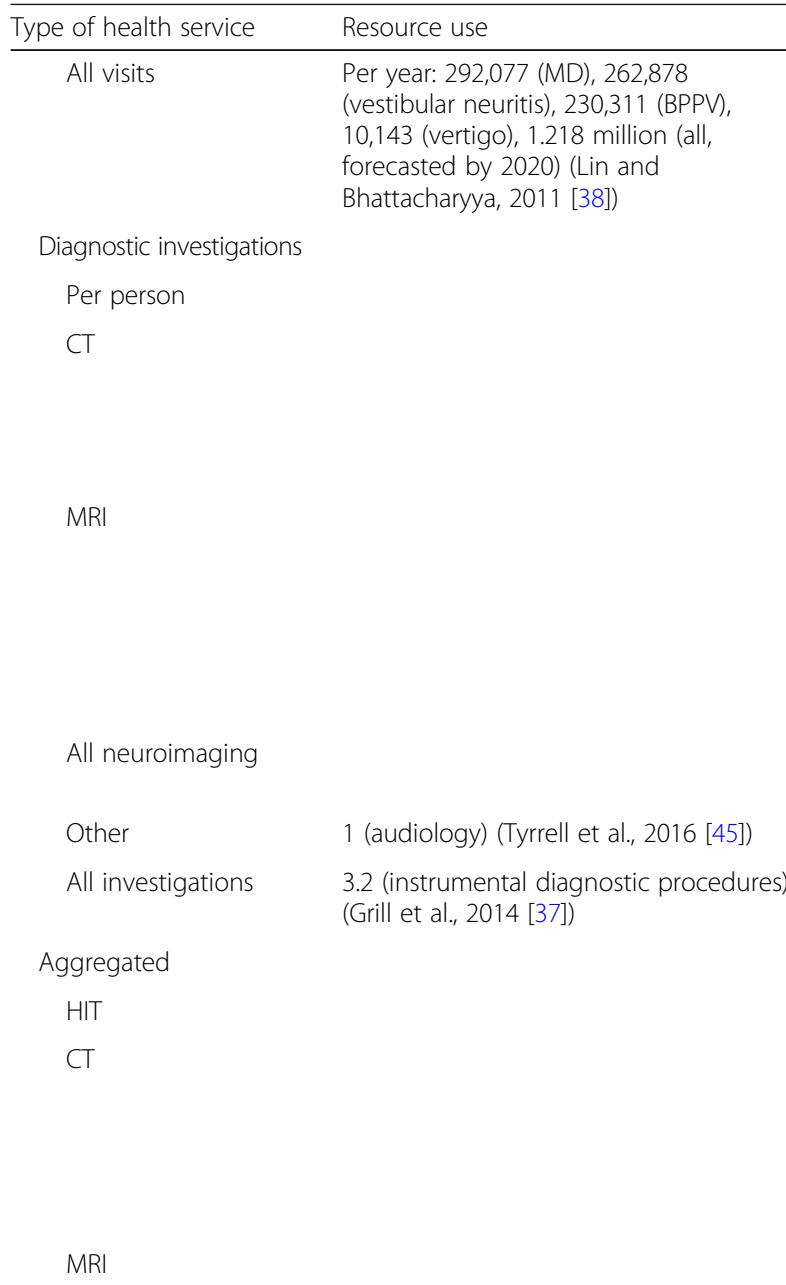

All neuroimaging

other

Therapy

Per person

Medication

10,143 (vertigo), 1.218 million (all,

(

Bhattacharyya, 2011 [38])
In \% for reported population

Costs [converted to 2016 USD ${ }^{\mathrm{a}}$ ]

In $\%$ for reported population

1220 [1265] USD, 164,700 [176,

720] USD (positive yield) (Ahsan

et al., 2013 [33]), 50,830 [54,540]

USD (positive yield) (Ammar

et al., 2017 [34])

2696 [2795] USD, 22,058 [23,668]

USD (positive yield) (Ahsan et al., 2013 [33]), 33,575 [36,025] USD (positive yield) (Ammar et al., 2017 [34]), 15,180 [15,737] USD (positive yield) (Gandolfi et al., 2015 [36])

$39.976[41,442]$ USD (positive yield) (Ahsan et al., 2013 [33])

5\% (McDowell and Moore, 2016 [39])

48\% (Ahsan et al., 2013 [33]), 42\% (Ammar et al., 2017 [34]), 31\% (episodic vertigo), 50.8\% (acute constant vertigo), $60.9 \%$ (chronic vertigo) (McDowell and Moore, 2016 [39])

9.5\%, (Ammar et al., 2017 [34]), 5.3\% (Ahsan et al., 2013 [33]), 18.6\% (Gandolfi et al., 2015 [36]), 1.2\% (episodic vertigo), 9\% (acute constant vertigo) (McDowell and Moore, 2016 [39]), 76.2\% (Grill et al., 2014 [37])

$12 \%$ (total costs, ED visits), trend from $10.0 \%$ in 1995 to $47.9 \%$ in 2015 (ED vertigo) (Saber Tehrani et al., 2013 [42]), 82\% (tertiary vertigo centre patients) (Grill et al., 2014 [37])

2.30\% (basic vestibular evaluation), 1.96\% (caloric test), 1.06\% (rotary chair test) (Adams et al., 2017 [32]), 59\% (complete neurological examination) (Ammar et al., 2017 [34]), 53.5\% (electrocardiography) (Grill et al., 2014 [37]), 31.4\% (DixHallpike manoeuvre) (McDowell and Moore, 2016 [39])
Per year: 360 [386] million USD (Saber Tehrani et al., 2013 [42]), 406,646 [436,324] USD (Ammar et al., 2017 [34])

Per 3 years: 988,200 [1,060,322] USD (Ahsan et al., 2013 [33])

Per year: 201,450 [216,153] USD (ED) (Ammar et al., 2017 [34]), 110 [118] million USD (Saber Tehrani et al., 2013 [42]), 0.38 [0.55] million GBP (MD, incident cases) (Tyrrell et al., 2016 [45]) Per 3 years: 242,640 [260,349] USD (ED) (Ahsan et al., 2013 [33]), $303,600[333,147]$ USD (ED) (Gandolfi et al., 2015 [36])

Per 3 years: 1,230,840 [1,275,985] USD (ED), 1,2 [1.24] million USD (potential savings on unremarkable imaging) (Ahsan et al., 2013 [33])

Per year: 0.15 [0.22] million GBP (hearing test, incident cases), 0.61 [0.89] million GBP (audiology) (Tyrrell et al., 2016 [45]) 
Table 2 Direct costs of vertigo (Continued)

\begin{tabular}{|c|c|c|c|}
\hline Type of health service & Resource use & In \% for reported population & Costs [converted to 2016 USDa] \\
\hline \multicolumn{4}{|l|}{ Aggregated } \\
\hline Medication & & $\begin{array}{l}\text { 61.0\% (all), 25.9\% (betahistine), 37.3\% } \\
\text { (homeopathic) (Grill et al., 2014 [37]), } \\
0.4 \% \text { - 45\% (prevention of attacks) } \\
\text { (Tyrrell et al., } 2016 \text { [45]), 44.6\% } \\
\text { (psychiatric, with comorbid anxiety), } \\
12.1 \% \text { (psychiatric, without comorbid } \\
\text { anxiety), 26.8\% (dizziness, with } \\
\text { comorbid anxiety), 13.5\% (dizziness, } \\
\text { without comorbid anxiety) (Wiltink } \\
\text { et al., } 2009 \text { [46]) }\end{array}$ & $\begin{array}{l}\text { Per year: } 7.90 \text { [11.72] million GBP } \\
\text { (all), } 4.19 \text { [6.21] million GBP } \\
\text { (betahistine), 1.76 [2.61] million } \\
\text { GBP (prochlorperazine), } 0.22 \\
\text { [0.33] million GBP } \\
\text { (bendrofluazide), } 1.63 \text { [2.42] } \\
\text { million GBP (cinnarizine), } 0.05 \\
\text { [0.07] million GBP (buccastem), } \\
\text { (0.06 [0.09] million GBP (cyclizine } \\
\text { (Tyrrell et al., } 2016 \text { [45]) }\end{array}$ \\
\hline Other & & $\begin{array}{l}\text { 15.3\% (Epley manoeuvre, BPPV) } \\
\text { (McDowell and Moore, } 2016 \text { [39]), } \\
21.4 \% \text { (psychotherapy with comorbid } \\
\text { anxiety), } 5.7 \% \text { (psychotherapy } \\
\text { without comorbid anxiety) (Wiltink } \\
\text { et al., } 2009 \text { [46]), } 41.3 \% \text { (physical } \\
\text { therapy) (Grill et al., } 2014 \text { [37]) }\end{array}$ & $\begin{array}{l}\text { Per year: } 3.1 \text { [4.6] million GBP } \\
\text { (hearing aids) (Tyrrell et al., } \\
2016 \text { [45]) }\end{array}$ \\
\hline \multicolumn{4}{|l|}{ Total direct cost } \\
\hline Per person & & & $\begin{array}{l}\text { Per year: } 35 \text { [53.79] GBP (routine } \\
\text { care) (Yardley et al., } 2012 \text { [47]) }\end{array}$ \\
\hline Aggregated & & & $\begin{array}{l}\text { Per year: } 61.3 \text { [89.26] million GBP } \\
\text { (Tyrrell et al., } 2016 \text { [45]) }\end{array}$ \\
\hline
\end{tabular}

BVD bilateral vestibular deficiency, BPPV Benign Paroxysmal Positional Vertigo, CT Computed Tomography, ED Emergency department, ENT ear-nose-throat, GBP Great Britain pound, HIT head impulse test, MRI Magnetic Resonance Imaging, MD Meniere's disease, USD United States dollar; UVD unilateral vestibular deficiency ${ }^{a}$ CCEMG - EPPI-Centre Cost Converter (Shemilt et al. 2010 [30])

\section{Indirect costs of vertigo}

Loss of working days (Table 3) ranged from 13.1 (SD 14.6) days during a 3 month observation period [35], to 69 (SD 106) days in 12 months [44], the latter corresponding to a mean productivity loss of 12,542 USD [44]. Sick leave was significantly higher in vestibular vertigo patients than in patients with non-vestibular vertigo [40]. Also, $69.8 \%$ of the patients reported they had to reduce their workload, $4.6 \%$ changed their job and 5.7\% quit work [35]. In Norway, almost $1 \%$ of the overall long-term sickness absence was caused by vertigo [43]. Among the affected patients, 23\% of women and 24\% of men obtained a disability pension [43].

Regarding non-monetary burden of disease, both vestibular vertigo patients and patients with non-vestibular vertigo reported avoiding leaving the house $(18.5 \%$ and $10.1 \%$, respectively), experienced an interruption of daily activities (40.3\% and $11.5 \%$, respectively), and perceived reduced quality of life [40] and relevant restrictions in daily life [44]. Concomitant anxiety was reported to further impair social life [46]. Patients with chronic vestibular loss reported an increased frequency of falls [44].

Two studies report on both direct and indirect cost, indicating that the latter may be even higher $[44,45]$.

\section{Total costs}

Two studies provided a wider view of the total cost of vertigo. A UK study [45] estimated as comprehensive cost of MD 3341-3757 GBP [4865 - 5470] per patients annually. A USA study included emergency visits and hospitalisation plus an estimation of lost working days, adding an average annual economic burden of 13,717 USD per BVD patients [44].

\section{Discussion}

This review is the first to explore the economic burden of vertigo and dizziness including direct and indirect costs. We found large heterogeneity in respect to the investigated sector of the health care system, the type of the vertigo, and the cost components; the quality of studies was mostly mediocre. Annually up to 9.6 visits were reported at the primary care provider [35], up to 7.2 visits at the specialist [35], with up to 6 instrumental diagnostic procedures [37]. Imaging was performed in up to $82 \%$ of the patients [37] with a cost of up to 164 , $700[176,720]$ USD per positive yield [33]. Up to 2.4 presentations occurred at the emergency department [35], leading to up to 6.8 hospital days [35]. The trend of the number of ED visits, and imaging due to the vertigo was rising $[38,42]$. Studies identified an increase by aging of the population in vertigo prevalence $[32,36,38]$, in vertigo-related health care demand [35, 38, 40, 42] and in imaging performed [33]; however, not in the number of other investigations [37].

The original studies reported three main drivers of increased direct costs: unnecessarily repeated consultations 
Table 3 Indirect costs of vertigo

\begin{tabular}{|c|c|c|c|}
\hline $\begin{array}{l}\text { Type of } \\
\text { burden }\end{array}$ & Resource use & In \% for reported population & Costs [converted to 2016 USDả \\
\hline \multicolumn{4}{|c|}{ Work / employment } \\
\hline Per person & $\begin{array}{l}\text { Within } 3 \text { months: lost work days } \\
13.1 \text { (Czech Republic), } 26.7 \text { (Germany), } \\
13.2 \text { (Hungary), } 15.8 \text { (Slovenia) } \\
\text { (Benecke et al., } 2013 \text { [35]) } \\
\text { Per year: lost work days } 69 \text { (BVD), } \\
19 \text { (UVD) (Sun et al., } 2014 \text { [44]) }\end{array}$ & & $\begin{array}{l}\text { Per year: 12,542 [13,214] USD (cost of lost work } \\
\text { days, BVD), } 3345 \text { [3524] USD (cost of lost work } \\
\text { days, UVD) (Sun et al., } 2014 \text { [44]) }\end{array}$ \\
\hline Aggregated & & $\begin{array}{l}\text { 41\% (sick leave, vestibular vertigo), 15\% (sick } \\
\text { leave, non-vestibular vertigo) (Neuhauser } \\
\text { et al., } 2008 \text { [40]) (Benecke et al., } 2013 \text { [35]) } \\
23 \% \text { (disability pension, female) and } 24 \% \\
\text { (disability pension, male) (Skoien et al., } \\
2008 \text { [43]) } \\
40 \% \text { (interruption of daily activities, vestibular } \\
\text { vertigo), 12\% (interruption of daily activities, } \\
\text { non-vestibular vertigo) (Neuhauser et al., } \\
2008 \text { [40]) }\end{array}$ & $\begin{array}{l}\text { Per year: } 2.87 \text { [4.26] million GBP (disability } \\
\text { benefit, MD), } 0.56 \text { [0.83] million GBP (additional } \\
\text { attendance allowance, MD), } 442.70 \text { [656.49] } \\
\text { million GBP (loss of earnings, MD-related } \\
\text { unemployment) (Tyrrell et al., } 2016 \text { [45]) }\end{array}$ \\
\hline \multicolumn{4}{|l|}{ Comorbidity } \\
\hline Per person & $\begin{array}{l}\text { Per year: } 19 \text { (falls, BDV), } 2 \text { (falls, UVD) } \\
\text { (Sun et al. } 2014 \text { [44]) }\end{array}$ & & \\
\hline Aggregated & & $\begin{array}{l}28.3 \% \text { (comorbid anxiety) (Wiltink et al., } \\
2009 \text { [46]) }\end{array}$ & $\begin{array}{l}\text { Per year: } 0.32 \text { [0.47] million GBP (depression } \\
\text { treatment), } 1.91 \text { [2.83] million GBP (depression } \\
\text { mortality), } 33.9 \text { [50.3] million GBP (pain and } \\
\text { suffering, median willingness to pay), } 101.48 \\
\text { [150.49] million GBP (pain and suffering, mean } \\
\text { willingness to pay) (Tyrrell et al., } 2016 \text { [45]) }\end{array}$ \\
\hline
\end{tabular}

BVD bilateral vestibular deficiency, GBP Great Britain pound, MD Meniere's disease, USD United States dollar, UVD unilateral vestibular deficiency ${ }^{a}$ CCEMG - EPPI-Centre Cost Converter (Shemilt et al. 2010 [30])

of primary, and specialist care, and referrals, where primary care would have been sufficient; excessive use of diagnostic imaging, and excessive use of emergency care, the latter mainly in countries where statutory affordable health insurance is not broadly available.

The number of referrals and consultations largely depends on the respective health care system. Typically, a system of statutory health insurance will regulate reconsultation and referral, however, in rather liberal systems such as Germany, referral is easy and sometimes more cost effective for the primary care physician [48]. Also, in an earlier study we found that primary care providers do not always feel competent to diagnose and treat vertigo [49]. Consequently, patients with vertigo may undergo several consultations and referrals without clear diagnosis or therapy $[6,35,40]$.

Second, several studies examined the excess costs of extensive imaging procedures $[33,34,42]$. It is reasonable to assume that physicians do not want to overlook life-threatening diseases. In absence of defined clinical pathways and in systems where imaging is broadly available, imaging seems like an easy solution. In contrast, low-cost examination techniques that require a certain skill set, such as the head impulse test [50] seem to be underutilized [39].
Third, consulting emergency care is not unusual because vertigo is a worrying symptom. However, overuse of the emergency department because of vertiginous symptoms may be a direct result of a system where primary care is not always affordable or available [51].

The limited data on indirect costs due to vertigo indicate that it may be considerable [35, 44, 45].

Considering the three main drivers of direct costs, there is no easy solution to the problem. Original studies recognising the problem of unnecessary or not welltargeted investigations argued for guidelines or managed care $[33,34,42]$. Application of clinical practice guidelines may provide benefit even in terms of preventing unnecessary diagnostic investigations, and supporting evidence-based resource use; thus, contributing to savings [52, 53]. The German Association for Primary Care has put forward a set of guidelines for management of vertigo in the primary care setting [54]. Likewise, guidelines exist in the USA [55], in the Netherlands [56], in Spain [57], in Croatia [58], or in China [59]. Treating vertigo frequently needs a multidisciplinary approach with combined expertise from several medical and therapeutic professions. Capacity building may reduce the vertigo-related direct costs through promoting evidencebased practices and increasing the knowledge base. 
However, due to the fragmentation of health care, PCPs often lack resources and time to coordinate such a team-based approach [60]. There is therefore an urgent need to focus economic research on the detected fields of main cost drivers, and investigate the effectiveness of care pathways and managed care approaches.

\section{Limitation}

The selected studies targeted various types of vestibular diseases and various cost components, providing a fragmented and incomplete picture. With respect to the limited number of cost reporting, we included studies reporting health care utilisation. Due to difficulties of finding historical unit price information, these were not converted to a monetised form. Though technical and equipment costs might be similar e.g. for imaging, other background aspects of national regulation and financing of the health care system may divert these prices in a broad range [61]. Thus, the financial burden may widely deviate in different countries even by similar prevalence of vertigo and similar frequency of health care utilisation. This limits the value of these data regarding the economic burden of vertigo. The gatekeeping function of primary care and the direct accessibility of specialist consultation is regulated differently depending on the country, thus, the utilisation of consultations on different levels of health care are not directly comparable.

\section{Conclusion}

To the best of our knowledge, this is the first systematic review of the existing evidence of the economic burden of vertigo. Results demonstrated that vertigo contributes to an increasing trend of direct health care costs, due to the ageing of the population. Three main cost drivers due to insufficient diagnostic skills were identified. Repeated and not well-targeted health care consultations on all levels, excessive use of expensive diagnostic imaging, and unnecessary assignment to emergency care. Several studies demonstrated that the ageing of the population contributes to an increasing trend of direct health care costs in persons with vertigo.

The main result, i.e. that there is no conclusive evidence expressing an overall economic burden, may seem disappointing at first. It is, however, the objective of any systematic review not only to summarize existing knowledge but also to summarize apparent gaps of evidence. There are several direct consequences from this gap:

1. Future studies of new or established diagnostic devices and therapies for vestibular disease should include cost-effectiveness considerations.

2. Population-based studies that focus on health care utilization should include simple assessments of vestibular function to get more reliable estimates of burden of disease and associated costs on the level of the general population.

3. Clinical and population-based registries that include patients with vestibular disease, should invest more effort in the exact characterization of disease and consider collecting long-term patient-reported outcomes, absence from work and other types of societal burden.

4. Primary data collection should increasingly include assessment of health care utilization e.g. by linking their diagnoses and outcomes to routine data from health insurances.

\section{Supplementary information}

Supplementary information accompanies this paper at https://doi.org/10. 1186/s13561-019-0258-2.

Additional file 1: Detailed search strategy.

Additional file 2. Assessment of study quality and risk of bias by the Consensus on Health Economic Criteria*.

\begin{abstract}
Abbreviations
BPPV: benign paroxysmal positional vertigo; BVD: bilateral vestibular deficiency; CCEMG - EPPI-Centre: The Campbell and Cochrane Economics Methods Group and the Evidence for Policy and Practice Information and Coordinating Centre; CHEC: Consensus on Health Economic Criteria; $\mathrm{CT}$ : computed tomography; ED: Emergency department; ENT: ear-nosethroat; GBP: Great Britain pound; HIT: head impulse test; ICD: International classification of diseases; MeSH: Medical Subject Headings; MD: Meniere's disease; MRI: magnetic resonance imaging; UK: United Kingdom; USA: United States of America; USD: United States dollar; UVD: unilateral vestibular deficiency
\end{abstract}

\section{Acknowledgements}

Not applicable.

Authors' contributions

EG conceptualised the study. EK and XW performed the study selection and the data extraction. EK analysed and interpreted the data and wrote the manuscript. All authors read and approved the final manuscript.

\section{Funding}

This work was supported by the Federal Ministry of Education and Research, Germany; grant number BMBF FKZ 01EO1401. The financial sponsor played no role in the design, execution, analysis and interpretation of data, or writing of the manuscript.

Availability of data and materials Not applicable.

Competing interests

The authors declare that they have no competing interests.

\section{Author details}

${ }^{1}$ Institute for Medical Information Processing, Biometrics and Epidemiology, Ludwig-Maximilians-Universität München, Munich, Germany. ${ }^{2}$ German Center for Vertigo and Balance Disorders, Faculty of Medicine, University Hospital, Ludwig-Maximilians-Universität München, Marchioninistr. 15, 81377 Munich, Germany. ${ }^{3}$ Munich Center of Health Sciences, Ludwig-Maximilians-Universität München, Marchioninistr. 15, 81377 Munich, Germany. 
Received: 7 March 2019 Accepted: 10 December 2019

Published online: 27 December 2019

\section{References}

1. Murdin L, Schilder AG. Epidemiology of balance symptoms and disorders in the community: a systematic review. Otol Neurotol. 2015;36(3):387-92.

2. Neuhauser HK. Epidemiology of vertigo. Curr Opin Neurol. 2007;20(1):40-6.

3. Strupp M, Brandt T. Diagnosis and treatment of vertigo and dizziness. Dtsch Arztebl Int. 2008;105(10):173-80.

4. Neuhauser HK. The epidemiology of dizziness and vertigo. Handb Clin Neurol. 2016;137:67-82.

5. Brandt T, Dieterich M, Strupp M. Vertigo and dizziness. Common complaints. London: Springer-Verlag; 2005.

6. Grill E, Penger M, Kentala E. Health care utilization, prognosis and outcomes of vestibular disease in primary care settings: systematic review. J Neurol. 2016;263(Suppl 1):S36-44.

7. Kruschinski C, Kersting M, Breull A, Kochen MM, Koschack J, HummersPradier E. Frequency of dizziness-related diagnoses and prescriptions in a general practice database. Z Evid Fortbild Qual Gesundhwes. 2008;102(5): 313-9.

8. Rieger A, Mansmann U, Maier W, Seitz L, Brandt T, Strupp M, et al. Management of patients with the cardinal symptom dizziness or vertigo. Gesundheitswesen. 2014;76(6):e32-8.

9. Luscher M, Theilgaard S, Edholm B. Prevalence and characteristics of diagnostic groups amongst 1034 patients seen in ENT practices for dizziness. J Laryngol Otol. 2014;128(2):128-33.

10. Guerra-Jimenez G, Arenas Rodriguez A, Falcon Gonzalez JC, Perez Plasencia $D$, Ramos Macias A. Epidemiology of vestibular disorders in the otoneurology unit. Acta Otorrinolaringol Esp. 2017;68(6):317-22.

11. Fernandez L, Breinbauer HA, Delano PH. Vertigo and dizziness in the elderly. Front Neurol. 2015;6:144.

12. Maarsingh OR, Dros J, Schellevis FG, van Weert HC, Bindels PJ, Horst HE. Dizziness reported by elderly patients in family practice: prevalence, incidence, and clinical characteristics. BMC Fam Pract. 2010;11:2

13. Lempert $\mathrm{T}$, Neuhauser $\mathrm{H}$. Epidemiology of vertigo, migraine and vestibular migraine. J Neurol. 2009;256(3):333-8.

14. Kroenke K, Hoffman RM, Einstadter D. How common are various causes of dizziness? A critical review. South Med J. 2000;93(2):160-7 quiz 8.

15. Brandt T, Strupp M, Dieterich M. Five keys for diagnosing most vertigo, dizziness, and imbalance syndromes: an expert opinion. J Neurol. 2014; 261(1):229-31.

16. Connor SE, Sriskandan N. Imaging of dizziness. Clin Radiol. 2014;69(2):111-22.

17. Epley JM. The canalith repositioning procedure: for treatment of benign paroxysmal positional vertigo. Otolaryngol Head Neck Surg. 1992;107(3): 399-404.

18. Semont A, Freyss G, Vitte E. Curing the BPPV with a liberatory maneuver. Adv Otorhinolaryngol. 1988;42:290-3.

19. Hilton MP, Pinder DK. The Epley (canalith repositioning) manoeuvre for benign paroxysmal positional vertigo. Cochrane Database Syst Rev. 2014; (12):Cd003162. https://doi.org/10.1002/14651858.CD003162.pub3.

20. Strupp M, Zwergal A, Feil K, Bremova T, Brandt T. Pharmacotherapy of vestibular and cerebellar disorders and downbeat nystagmus: translational and back-translational research. Ann N Y Acad Sci. 2015;1343:27-36.

21. Kundakci B, Sultana A, Taylor AJ, Alshehri MA. The effectiveness of exercisebased vestibular rehabilitation in adult patients with chronic dizziness: a systematic review. F1000Research. 2018;7:276.

22. Hall CD, Herdman SJ, Whitney SL, Cass SP, Clendaniel RA, Fife TD, et al. Vestibular rehabilitation for peripheral vestibular hypofunction: an evidencebased clinical practice guideline: FROM THE AMERICAN PHYSICAL THERAPY ASSOCIATION NEUROLOGY SECTION. J Neurol Phys Ther. 2016;40(2):124-55.

23. Bronstein AM, Golding JF, Gresty MA, Mandala M, Nuti D, Shetye A, et al. The social impact of dizziness in London and Siena. J Neurol. 2010;257(2): 183-90.

24. van der Zaag-Loonen HJ, van Leeuwen RB. Dizziness causes absence from work. Acta Neurol Belg. 2015;115(3):345-9.

25. Ciorba A, Bianchini C, Scanelli G, Pala M, Zurlo A, Aimoni C. The impact of dizziness on quality-of-life in the elderly. Eur Arch Otorhinolaryngol. 2017; 274(3):1245-50.

26. Agrawal Y, Pineault KG, Semenov YR. Health-related quality of life and economic burden of vestibular loss in older adults. Laryngoscope Investig Otolaryngol. 2018;3(1):8-15.
27. Moher D, Liberati A, Tetzlaff J, Altman DG. Preferred reporting items for systematic reviews and meta-analyses: the PRISMA statement. Ann Intern Med. 2009;151(4):264-9 w64.

28. Composition of macro geographical (continental) regions, geographical sub-regions, and selected economic and other groupings. United Nations Statistics Division 2010 [Available from: https://unstats.un.org/unsd/ methodology/m49/.

29. Evers S, Goossens $M$, de Vet $H$, van Tulder M, Ament A. Criteria list for assessment of methodological quality of economic evaluations: consensus on health economic criteria. Int J Technol Assess Health Care. 2005;21(2): $240-5$.

30. SHEMILTI, THOMAS J, MORCIANO M. A web-based tool for adjusting costs to a specific target currency and price year. Evid Policy. 2010;6:51-9.

31. Higgins J, Green S. Cochrane handbook for systematic reviews of Interventions Version 5.1.0 the cochrane collaboration; 2011 [Available from: http://handbook.cochrane.org.

32. Adams ME, Marmor S, Yueh B, Kane RL. Geographic variation in use of vestibular testing among Medicare beneficiaries. Otolaryngol Head Neck Surg. 2017;156(2):312-20.

33. Ahsan SF, Syamal MN, Yaremchuk K, Peterson E, Seidman M. The costs and utility of imaging in evaluating dizzy patients in the emergency room. Laryngoscope. 2013;123(9):2250-3.

34. Ammar H, Govindu R, Fouda R, Zohdy W, Supsupin E. Dizziness in a community hospital: central neurological causes, clinical predictors, and diagnostic yield and cost of neuroimaging studies. J Commun Hosp Intern Med Perspect. 2017;7(2):73-8.

35. Benecke H, Agus S, Kuessner D, Goodall G, Strupp M. The burden and impact of Vertigo: findings from the REVERT patient registry. Front Neurol. 2013:4:136.

36. Gandolfi MM, Reilly EK, Galatioto J, Judson RB, Kim AH. Cost-effective analysis of unilateral vestibular weakness investigation. Otol Neurotol. 2015; 36(2):277-81.

37. Grill E, Strupp M, Muller M, Jahn K. Health services utilization of patients with vertigo in primary care: a retrospective cohort study. J Neurol. 2014; 261(8):1492-8.

38. Lin HW, Bhattacharyya N. Otologic diagnoses in the elderly: current utilization and predicted workload increase. Laryngoscope. 2011;121(7): 1504-7.

39. McDowell T, Moore F. The under-utilization of the head impulse test in the emergency department. Can J Neurol Sci. 2016:43(3):398-401.

40. Neuhauser HK, Radtke A, von Brevern M, Lezius F, Feldmann M, Lempert T. Burden of dizziness and vertigo in the community. Arch Intern Med. 2008; 168(19):2118-24.

41. Reddy VM, Sargent H, Prior MJ. Benign paroxysmal positional vertigo nurseled follow-up clinic. Eur Arch Otorhinolaryngol. 2011;268(6):829-32.

42. Saber Tehrani AS, Coughlan D, Hsieh YH, Mantokoudis G, Korley FK, Kerber KA, et al. Rising annual costs of dizziness presentations to U.S. emergency departments. Acad Emerg Med Off J Soc Acad Emerg Med. 2013;20(7):689-96.

43. Skoien AK, Wilhemsen K, Gjesdal S. Occupational disability caused by dizziness and vertigo: a register-based prospective study. Br J Gen Pract. 2008:58(554):619-23.

44. Sun DQ, Ward BK, Semenov YR, Carey JP, Della Santina CC. Bilateral vestibular deficiency: quality of life and economic implications. JAMA Otolaryngol Head Neck Surg. 2014;140(6):527-34.

45. Tyrrell J, Whinney DJ, Taylor T. The cost of Meniere's disease: a novel multisource approach. Ear Hear. 2016;37(3):e202-9.

46. Wiltink J, Tschan R, Michal M, Subic-Wrana C, Eckhardt-Henn A, Dieterich M, et al. Dizziness: anxiety, health care utilization and health behavior--results from a representative German community survey. J Psychosom Res. 2009; 66(5):417-24.

47. Yardley L, Barker F, Muller I, Turner D, Kirby S, Mullee M, et al. Clinical and cost effectiveness of booklet based vestibular rehabilitation for chronic dizziness in primary care: single blind, parallel group, pragmatic, randomised controlled trial. BMJ. 2012;344:e2237.

48. Harris M, Vedsted P, Esteva M, Murchie P, Aubin-Auger I, Azuri J, et al. Identifying important health system factors that influence primary care practitioners' referrals for cancer suspicion: a European cross-sectional survey. BMJ Open. 2018:8(9):e022904.

49. Stephan AJ, Kovacs E, Phillips A, Schelling J, Ulrich SM, Grill E. Barriers and facilitators for the management of vertigo: a qualitative study with primary care providers. Implement Sci. 2018;13(1):25. 
50. Newman-Toker DE, Curthoys IS, Halmagyi GM. Diagnosing stroke in acute Vertigo: the HINTS family of eye movement tests and the future of the "eye ECG". Semin Neurol. 2015;35(5):506-21.

51. van den Berg MJ, van Loenen T, Westert GP. Accessible and continuous primary care may help reduce rates of emergency department use. An international survey in 34 countries. Fam Pract. 2016;33(1):42-50.

52. Kosimbei G, Hanson K, English M. Do clinical guidelines reduce clinician dependent costs? Health Res Policy Syst. 2011;9:24.

53. Moran AE, Odden MC, Thanataveerat A, Tzong KY, Rasmussen PW, Guzman D, et al. Cost-effectiveness of hypertension therapy according to 2014 guidelines. N Engl J Med. 2015;372(5):447-55.

54. Abholz H-H, Jendyk R. Akuter Schwindel in der Hausarztpraxis. S3-Leitlinie. Berlin: Deutsche Gesellschaft für Allgemeinmedizin und Familienmedizin (DEGAM); 2016.

55. Bhattacharyya N, Gubbels SP, Schwartz SR, Edlow JA, El-Kashlan H, Fife T, et al. Clinical practice guideline: benign paroxysmal positional vertigo (update). Otolaryngol Head Neck Surg. 2017;156(3_suppl):S1-S47.

56. van Lieshout J, Assendelft WJ. Summary of the Dutch College of General Practitioners' practice guideline 'dizziness'. Ned Tijdschr Geneeskd. 2003; 147(8):331-5.

57. Perez-Vazquez P, Franco-Gutierrez V, Soto-Varela A, Amor-Dorado JC, MartinSanz E, Oliva-Dominguez M, et al. Practice guidelines for the diagnosis and management of benign paroxysmal positional vertigo otoneurology committee of Spanish otorhinolaryngology and head and neck surgery consensus document. Acta Otorrinolaringol Esp. 2018;69(6):345-66.

58. Maslovara S, Butkovic-Soldo S, Drvis P, Roje-Bedekovic M, Trotic R, Branica S, et al. Croatian guidelines for diagnosis and management of benign paroxysmal positional vertigo (BPPV). Lijec Vjesn. 2015;137(11-12):335-42.

59. Association SoOHaNSCM. Guideline of diagnosis and treatment of benign paroxysmal positional vertigo (2017). Zhonghua Er Bi Yan Hou Tou Jing Wai Ke Za Zhi. 2017;52(3):173-7.

60. Kovacs E, Strobl R, Phillips A, Stephan AJ, Muller M, Gensichen J, et al. Systematic review and meta-analysis of the effectiveness of implementation strategies for non-communicable disease guidelines in primary health care. J Gen Intern Med. 2018;33(7):1142-54.

61. Papanicolas I, Woskie LR, Jha AK. Health care spending in the United States and other high-income countries. JAMA. 2018;319(10):1024-39.

\section{Publisher's Note}

Springer Nature remains neutral with regard to jurisdictional claims in published maps and institutional affiliations.

Ready to submit your research? Choose BMC and benefit from:

- fast, convenient online submission

- thorough peer review by experienced researchers in your field

- rapid publication on acceptance

- support for research data, including large and complex data types

- gold Open Access which fosters wider collaboration and increased citations

- maximum visibility for your research: over $100 \mathrm{M}$ website views per year

At $\mathrm{BMC}$, research is always in progress.

Learn more biomedcentral.com/submissions 